\title{
Numerical Simulation of PRHR System Based on CFD
}

\author{
Bin Jia, Jianping Jing, Xuedong Qiao, Chunming Zhang \\ Nuclear and Radiation Safety Center, Beijing, China \\ Email: athrun_jin@163.com
}

Received September 2013

\begin{abstract}
In this paper numerical simulation of PRHR HX and IRWST is demonstrated using FLUENT, and different numbers of C-type heat transfer tubes and coolant inlet temperature's effects for the residual heat removal capacity of PRHR HX, IRWST thermal stratification and natural circulation have been researched. It's found that at a constant flow area when heat transfer tubes' number increased outlet temperature of PRHR HX is lower, the whole water temperature of IRWST is higher, thermal stratification and natural circulation are more oblivious. At a constant mass flow when inlet temperature of PRHR HX increased, inlet flow velocity increases and outlet temperature is higher. But on the other hand the cooling rate increases at the same time, the average temperature of IRWST is higher, the range of thermal stratification expands and the velocity of natural circulation increases.
\end{abstract}

Keywords: PRHR HX; IRWST; Numerical Simulation; FLUENT; C-Type Heat Transfer Tubes

\section{Introduction}

Introducing passive concept into safety systems is typical character for the $3^{\text {rd }}$ generation nuclear power plant. Currently many reactors under construction or under design use lots of this advanced concept both domestically and abroad.

AP1000 passive residual heat removal system [1] (PRHRS) is one of the important passive safety systems, it can take the advantage of the coolant density difference between in-core and C-type heat transfer tubes of passive residual heat removal heat exchanger (PRHR HX) as a driving force to establish natural circulation, and transfer heat to in-containment refueling water storage tank (IRWST) through PRHR HX, then remove the residual heat in the core under accident conditions and ensure the safety of the reactor. As two key devices in the system PRHR HX and IRWST directly affect whether the residual heat in the core can be removed under accident conditions, so it's necessary to research PRHR HX heat transfer performance and IRWST internal thermal stratification and natural circulation.

With advances in computer hardware technology and rapid development in computational fluid dynamics (CFD), it has become a very effective techniques that using numerical simulation to carry out fluid flow and heat transfer research for various heat exchangers [2,3]. Therefore in this paper numerical simulation for PRHR HX and IRWST has been taken via Fluent software, and our focus is the effect for PRHR HX heat transfer performance and IRWST internal thermal stratification and natural circulation when the C-type heat transfer tubes' number or the coolant inlet temperature changes.

\section{Research Subjects and Mathematical Models}

\subsection{Research Subjects}

In this paper AP1000 is seen as an example designed by Westinghouse, its PRHR HX is consisted of 689 bundle arranged C-type heat transfer tubes, inlet head and outlet head. Heat exchanger is submerged in IRWST, and it can remove residual heat from core by transferring it to IRWST in operation. In Table 1 parameter $[1,4,5]$ of IRWST and PRHR HX are listed, Figure $\mathbf{1}$ is the PRHR system diagram.

Firstly on the basis of AP1000 PRHR HX various geometric, operating design parameters modeling and calculation are carried out. Though PRHR HX is consisted of lots of heat transfer tubes, but each tube's heat transfer process is relatively independent, heat transfer mechanism is the same. To reduce the amount of computation and research the effects of different number of C-type heat transfer tubes for PRHRS operation, and on the basis of total flow area unchanged and through changing tube size, physical models of 8-tube and 16-tube heat exchangers submerged in cubic IRWST are built respectively, as showed in Figure 2. Then on the basis of calculation result of 16-tube model at design 
Table 1. Parameters for IRWST and PRHR HX of AP1000.

\begin{tabular}{|c|c|c|c|}
\hline \multicolumn{2}{|c|}{ IRWST } & \multicolumn{2}{|c|}{ PRHR HX } \\
\hline parameter & number & parameter & number \\
\hline Minimum water capacity $\left(\mathrm{m}^{3}\right)$ & 2092 & Heat load(J/s) & $5.89 \mathrm{E}+07$ \\
\hline Actual water capacity $\left(\mathrm{m}^{3}\right)$ & 2132 & Design flow(kg/h) & $2.28 \mathrm{E}+05$ \\
\hline Design temperature $\left({ }^{\circ} \mathrm{C}\right)$ & 65.6 & Outlet water temperature $\left({ }^{\circ} \mathrm{C}\right)$ & 92.8 \\
\hline IRWST initial temperature $\left({ }^{\circ} \mathrm{C}\right)$ & 48.9 & Design pressure(Mpa) & 17.1 (Measuring) \\
\hline Normal depth, mm & 8534.4 & Heat exchanger inlet pressure(Mpa) & 15.5 \\
\hline Nominal depth, mm & 8778.2 & Design temperature $\left({ }^{\circ} \mathrm{C}\right)$ & 343.3 \\
\hline \multirow[t]{4}{*}{ Material } & Stainless steel & Number of heat transfer tubes & 689 \\
\hline & & Size of heat transfer tubes(mm) & $19.05 * 1.65$ \\
\hline & & Spacing of heat transfer tubes(mm) & 38 \\
\hline & & Material & 690Alloy \\
\hline
\end{tabular}

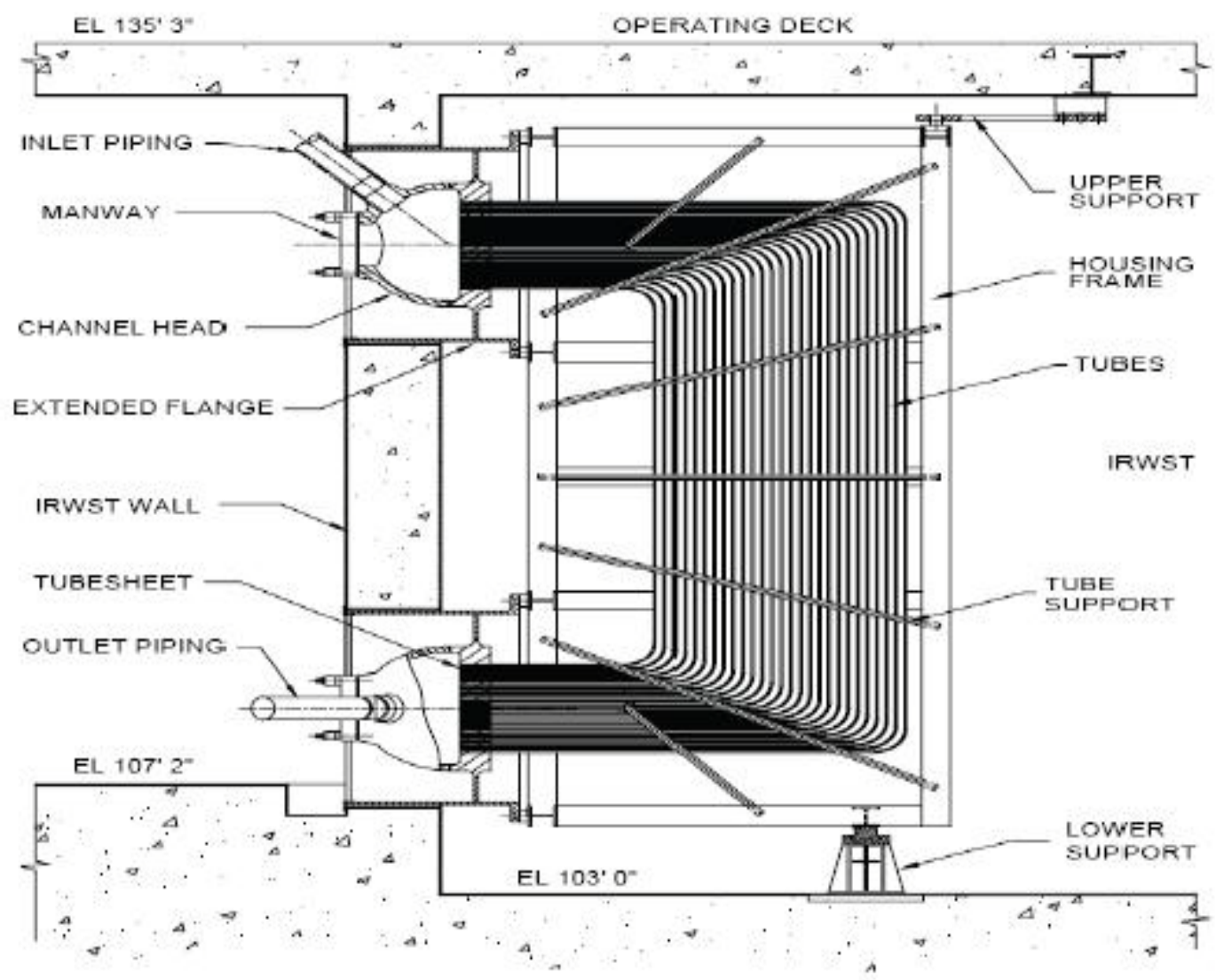

Figure 1. Schematic diagram of PRHR system.

operating condition, through changing coolant inlet temperature to research the effects for heat exchanger per- formance and IRWST stratification phenomena and natural circulation and master the law for much more heat 


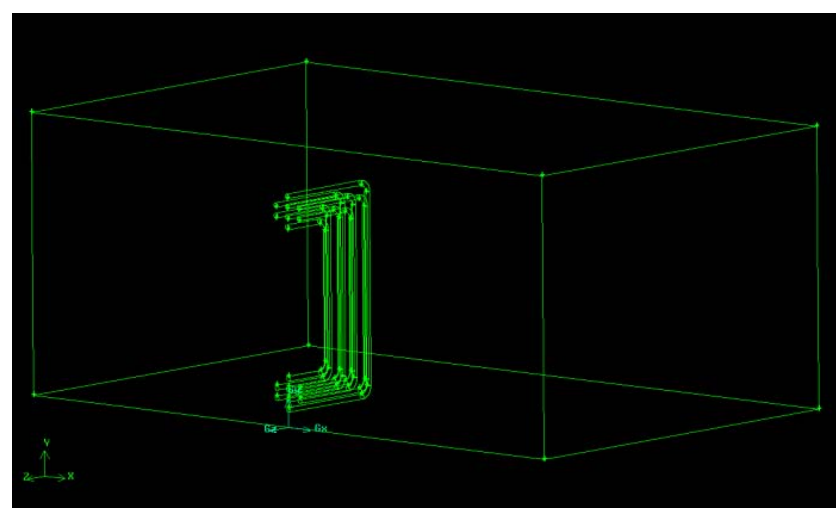

(a)

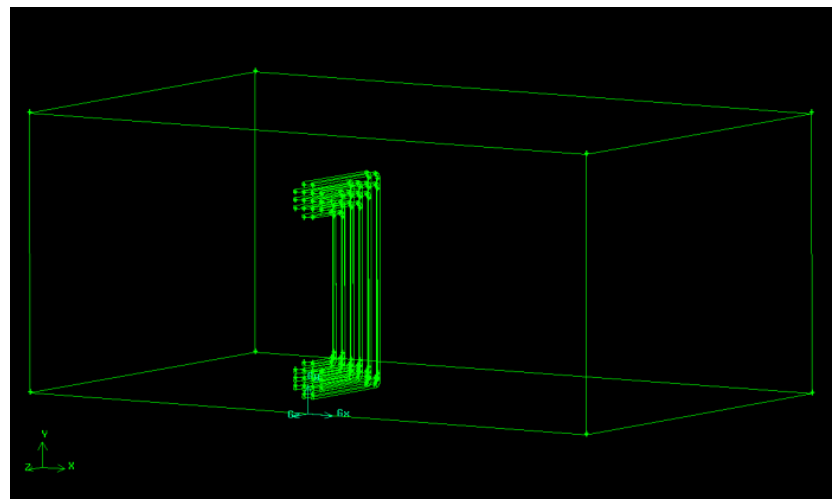

(c)

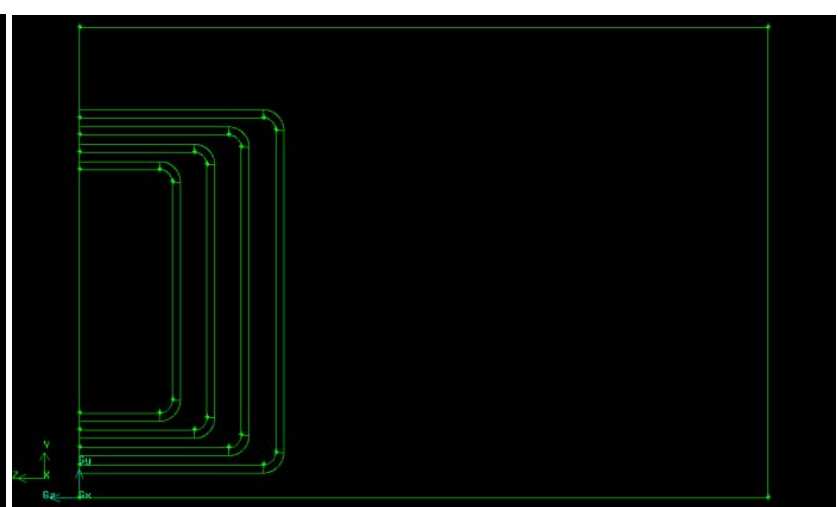

(b)

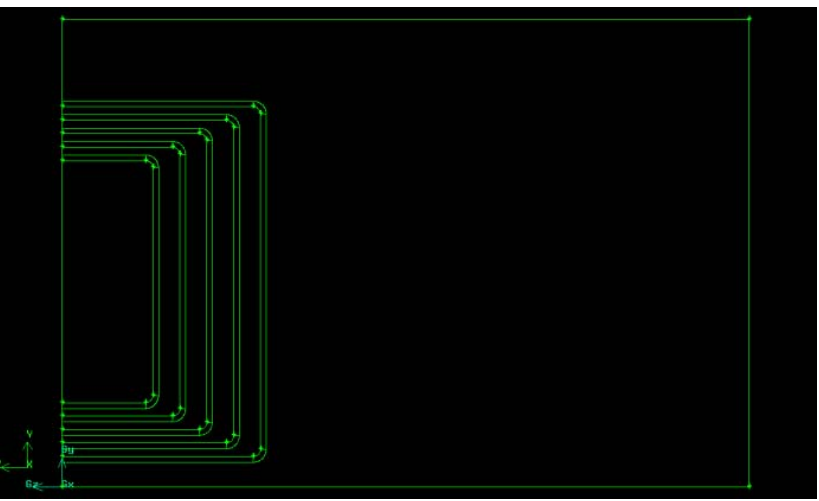

(d)

Figure 2. Diagram of system model, (a) and (b) for 8 tubes, (c) and (d) for 16 tubes.

transfer tubes modeling and calculation in future.

\subsection{Mathematical Models}

Since there is a big temperature difference between water in heat exchanger C-type tubes and water in IRWST, turbulence phenomenon will happen in the heat exchanger. Because of that, to close the Reynolds-averaged N - S equations, a turbulence model is necessary and $\mathrm{k}-\varepsilon$ equation is used, the corresponding equations are as follows $[6,7]$.

Continuity equation:

$$
\frac{\partial \rho}{\partial t}+\nabla(\rho u)=S_{m}
$$

Momentum equation:

$$
\rho\left(\frac{\partial u}{\partial t}+u \cdot \nabla u\right)=\rho f+\nabla \cdot \sigma
$$

Energy equation:

$$
\begin{aligned}
& \rho c_{p}\left(\frac{\partial T}{\partial t}+u \cdot \nabla T\right)+p \nabla u \\
& =(\nabla \lambda \cdot \nabla) T+\rho q-\nabla q_{r}+\phi
\end{aligned}
$$

$\mathrm{k}-\varepsilon$ equation:

$$
\begin{aligned}
& \frac{\partial(\rho k)}{\partial t}+\frac{\partial\left(\rho u_{j} k\right)}{\partial x_{j}} \\
& =p-\rho \varepsilon+\frac{\partial}{\partial x_{j}}\left[\left(\mu+\frac{\mu_{t}}{\sigma_{k}}\right) \frac{\partial k}{\partial x_{j}}\right] \\
& \frac{\partial(\rho \varepsilon)}{\partial t}+\frac{\partial\left(\rho u_{j} \xi\right)}{\partial x_{j}}=C_{\xi 1} \frac{\xi}{k} P_{t}-C_{\xi 2} \rho \frac{\xi^{2}}{k} \\
& +\frac{\partial}{\partial x_{j}}\left[\left(\mu+\frac{\mu_{t}}{\sigma_{\varepsilon}}\right) \frac{\partial \xi}{\partial x_{j}}\right] \\
& \mu_{t}=\frac{C_{\mu} \rho k^{2}}{\xi}
\end{aligned}
$$

In the formula: $\mathrm{Sm}$ is the source term, $u$ is the flow velocity, $\lambda$ is the thermal conductivity, $q r$ is the heat transfer. For the $\mathrm{k}-\varepsilon$ equation, $k$ and $\varepsilon$ are turbulent kinetic energy and turbulent dissipation rate, $P_{t}$ is the turbulent kinetic energy production term, $\mu_{t}$ is the turbulent viscosity coefficient, model constants are: $C_{\xi 1}=1.44, C_{\xi 2}$ $=1.92, \sigma_{k}=1.0, \sigma_{\varepsilon}=1.3, C_{\mu}=0.09$.

As the temperature of the coolant through the heat exchanger will be drastically reduced, while the refueling water tank will be heated, water temperature changing will directly cause changing in density, thereby affecting 
the entire natural circulation and heat transfer process. So water density varied with temperature udf relation [8] is introduced into material properties table in FLUENT program. Since the density of water reaches the maximum at $3.98^{\circ} \mathrm{C}$ atmospheric pressure, density and temperature parabolic relation are selected:

$$
\rho=\rho_{0}\left[1-\gamma\left(T-T_{0}\right)^{2}\right]
$$

In the formula: $\rho_{0}$ is the maximum value of water density, $T_{0}$ is the water temperature at the same time, $\gamma$ is the thermal expansion coefficient. Although PRHR HX design pressure is $16.9 \mathrm{Mpa}$, design temperature is $297.2^{\circ} \mathrm{C}$, and the IRWST runs at atmospheric pressure, the design temperature is $48.9^{\circ} \mathrm{C}$. However after verification, it's found that thermal expansion coefficients at two conditions are very close, with little effect on the calculation, the final $\gamma$ is selected as $3.1 \mathrm{e}^{-6}$.

\section{Simulation Results}

\subsection{Effect of Different C-Type Heat Transfer Tubes Number}

At design parameters 8-tube and 16-tube heat exchanger models outlet temperature is demonstrated in Table $\mathbf{2}$, tube number is according to system model Figure 2 from left to right and from top to bottom in order. It can be seen from both sets of data that because of long stroke for outer tubes, their cooling effect is better than inner ones'. Though comparing it's found that whether the characteristic tube or the average value the outlet temperature of 16-tube model is obviously lower than 8-tube. The reason is that on the basis of certain flow area increasing tube number means heat transfer area increases. Further heat transfer will be enhanced and performance of the heat exchanger will be improved.

The internal thermal stratification diagram of IRWST is showed in Figure 3, respectively longitudinal direction slitting figure along the width of the tank and transverse direction slitting figure along the height of the tank, Figures 3(a) and (c) are for 8-tube model, Figures 3(b) and d are for 16-tube model. By contrast, the thermal stratification phenomenon of 16-tube model is more obvious, the temperature of high temperature area is higher and the range is larger, from Figure 3(d) it can be seen that thermal stratification has basically spread throughout the tank section.

\subsection{Effect of Different Coolant Inlet Temperature}

On the basis of 16-tube model effect of different coolant inlet temperature has been researched. Coolant outlet temperature changing through changing inlet temperature is demonstrated in Table 3. It's found that when inlet temperature increases the outlet temperature also increases. The reason is that when the whole flow is constant, increasing inlet temperature means increasing heat input, but the water loaded in IRWST is unchanged, so the outlet temperature will become higher.

Although with the inlet temperature increasing the outlet temperature has a clear upward trend, but PRHR HX cooling rate is increased too, the cooling rate equation is as follows.

$$
\frac{T_{\text {inlet }}-T_{\text {outlet }}}{T_{\text {inlet }}} \times 100 \%
$$

$T_{\text {inlet }}$ and $T_{\text {outlet }}$ are coolant inlet and outlet temperature respectively. By calculation, when the inlet temperature is $275^{\circ} \mathrm{C}, 297.2^{\circ} \mathrm{C}$ and $325^{\circ} \mathrm{C}$, the cooling rate is $24.99 \%$, $25.87 \%$ and $26.87 \%$. The reason is that when whole flow is constant, coolant volume will expand with higher temperature, and meanwhile the flow area is also constant the flow velocity of the coolant will improve. Thus the heat transfer coefficient [9] between the coolant and heat transfer tube wall will be increased and the heat transfer performance of PRHR HX will be enhanced.

Figures 4(a)-(c) and (d)-(f) are the internal thermal stratification diagrams of IRWST when temperature is $275^{\circ} \mathrm{C}, 297.2^{\circ} \mathrm{C}$ and $325^{\circ} \mathrm{C}$ and respectively longitudinal direction slitting figure along the width of the tank and transverse direction slitting figure along the height of the tank. When the coolant inlet temperature increases the water temperature of IRWST is also changing, the range of thermal stratification is expanding gradually, it means that the utilization of IRWST is improving. So once again it confirms that with inlet temperature rising

\begin{tabular}{|c|c|c|c|c|c|c|c|c|c|}
\hline Unit $\left({ }^{\circ} \mathrm{C}\right)$ & Tube 1 & Tube 2 & Tube 3 & Tube 4 & Tube 5 & Tube 6 & Tube 7 & Tube 8 & Average \\
\hline Outlet temperature(8) & 224.06 & 232.02 & 236.22 & 231.95 & 240.75 & 244 & 240.78 & 249.81 & 237.45 \\
\hline \multirow{4}{*}{ Outlet temperature(16) } & Tube 1 & Tube 2 & Tube 3 & Tube 4 & Tube 5 & Tube 6 & Tube 7 & Tube 8 & \multirow{4}{*}{220.32} \\
\hline & 201.68 & 201.67 & 209.72 & 213.39 & 213.52 & 209.76 & 219.29 & 224.03 & \\
\hline & Tube 9 & Tube10 & Tube 11 & Tube 12 & Tube 13 & Tube 14 & Tube 15 & Tube 16 & \\
\hline & 224.07 & 219.39 & 227.69 & 230.24 & 230.17 & 227.51 & 236.44 & 236.57 & \\
\hline
\end{tabular}

Table 2. Outlet temperature of 8 and 16 tubes models at designed inlet temperature. 

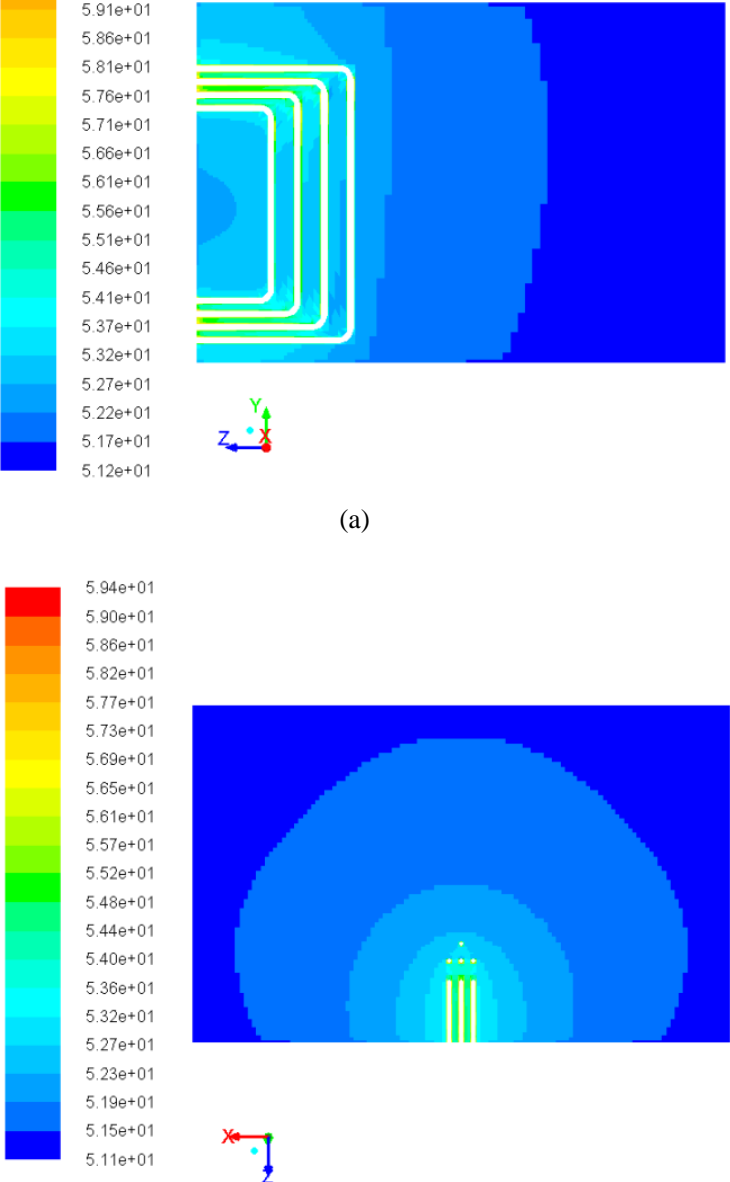

(c) (a)

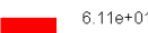

$6.06 e+01$

$6.01 \mathrm{e}+01$

$5.96 \mathrm{e}+01$

$5.91 e+01$

$5.86 \theta+01$

$5.81 e+01$

$5.77 e+01$

$5.720+01$

$5.67 \Theta+01$

$5.62 e+01$

$5.57 \mathrm{e}+0$

$5.52 \mathrm{e}+01$

$5.47 \mathrm{e}+01$

$542 e+01$

$5.37 \mathrm{e}+0$

$5.32 \mathrm{e}+01$

$5.27 \mathrm{e}+01$

$5.22 \mathrm{e}+01$

$5.18 \mathrm{e}+01$

$5.13 e+0$

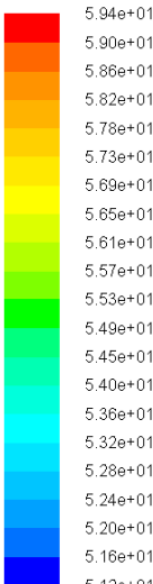

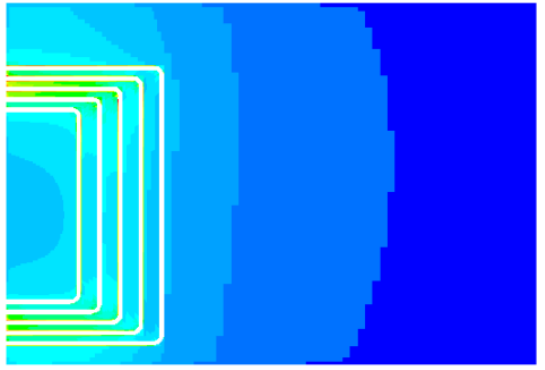

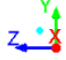

(b)
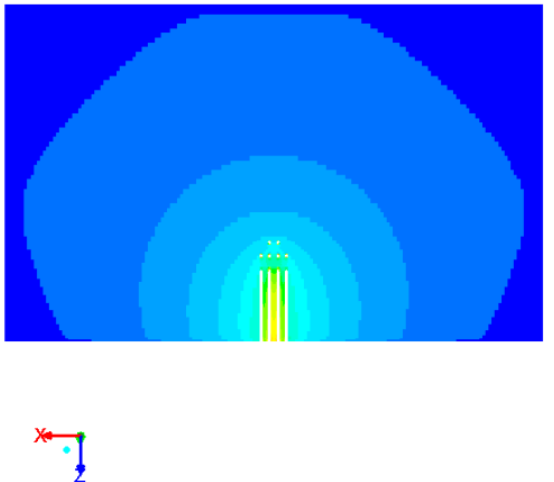

(d)

Figure 3. IRWST thermal stratification, (a) and (c) for 8 tubes, (b) and (d) for 16 tubes.

Table 3. Outlet temperature of $\mathbf{1 6}$ tubes model at different inlet temperature.

\begin{tabular}{|c|c|c|c|c|c|c|c|c|c|}
\hline Unit $\left({ }^{\circ} \mathrm{C}\right)$ & Tube 2 & Tube 4 & Tube 6 & Tube 8 & Tube10 & Tube12 & Tube14 & Tube16 & Average \\
\hline Outlet temperature $\left(275^{\circ} \mathrm{C}\right)$ & 189.65 & 200.07 & 197.03 & 209.39 & 205.44 & 215.17 & 212.86 & 220.75 & 206.27 \\
\hline Outlet temperature $\left(297.2^{\circ} \mathrm{C}\right)$ & 201.67 & 213.39 & 209.76 & 224.03 & 219.39 & 230.24 & 227.51 & 236.57 & 220.32 \\
\hline Outlet temperature $\left(325^{\circ} \mathrm{C}\right)$ & 216.49 & 229.98 & 225.56 & 242.04 & 236.64 & 248.89 & 245.7 & 256.22 & 237.68 \\
\hline
\end{tabular}

PRHRS performance is improved.

At the above three conditions velocity vector of natural circulation phenomena in IRWST is showed in Figure 5. Figures 5(a)-(c) are respectively corresponding to the inlet temperature $275^{\circ} \mathrm{C}, 297.2^{\circ} \mathrm{C}$ and $325^{\circ} \mathrm{C}$.

When the water in IRWST is heated by PRHR HX, not only thermal stratification is built but also density stratification. Near the heat transfer tubes the temperature is higher and density decreases natural convection phenomena will occur. Meanwhile at the area that far away from the tubes but near the inner wall of IRWST the water temperature is relatively lower and density is relatively higher, then the natural circulation phenomena will be generated within the whole tank. As showed in Figure 5, with the increasing of coolant inlet temperature heat transfer inside IRWST is improved and velocity of natural circulation is increasing gradually, thus the heat transfer coefficient [9] between the coolant and heat transfer tube wall will be increased and the heat transfer performance of PRHR HX will be enhanced further. 

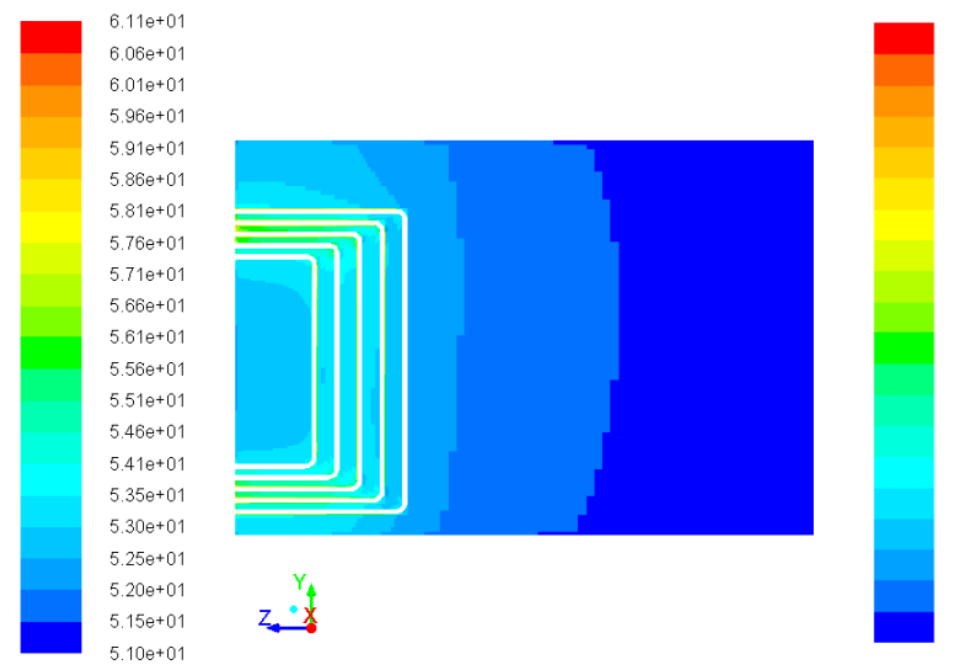

$5.94 e+01$
$5.90 e+01$
$5.86 e+01$
$5.81 e+01$
$5.77 e+01$
$5.73 e+01$
$5.69 e+01$
$5.64 e+01$
$5.60 \Theta+01$
$5.56 e+01$
$5.52 e+01$
$5.47 e+01$
$5.43 e+01$
$5.39 e+01$
$5.35 e+01$
$5.31 e+01$
$5.26 e+01$
$5.22 e+01$
$5.18 e+01$
$5.14 \Theta+01$
$5.09 e+01$

(a)
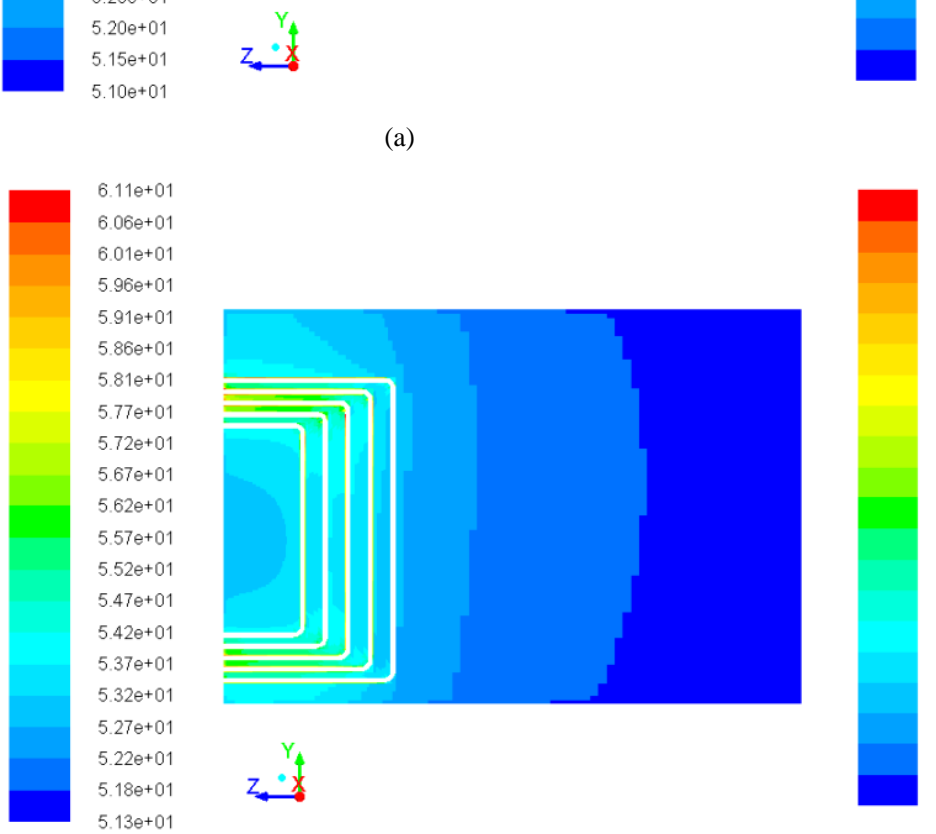

$5.94 \mathrm{e}+01$
$5.90 \mathrm{e}+01$
$5.86 \mathrm{e}+01$
$5.82 \mathrm{e}+01$
$5.78 \mathrm{e}+01$
$5.73 \mathrm{e}+01$
$5.69 \mathrm{e}+01$
$5.65 \mathrm{e}+01$
$5.61 \mathrm{e}+01$
$5.57 \mathrm{e}+01$
$5.53 \mathrm{e}+01$
$5.49 \mathrm{e}+01$
$5.45 \mathrm{e}+01$
$5.40 \mathrm{e}+01$
$5.36 \mathrm{e}+01$
$5.32 \mathrm{e}+01$
$5.28 \mathrm{e}+01$
$5.24 \mathrm{e}+01$
$5.20 \mathrm{e}+01$
$5.16 \mathrm{e}+01$
$5.12 \mathrm{e}+01$

(c)

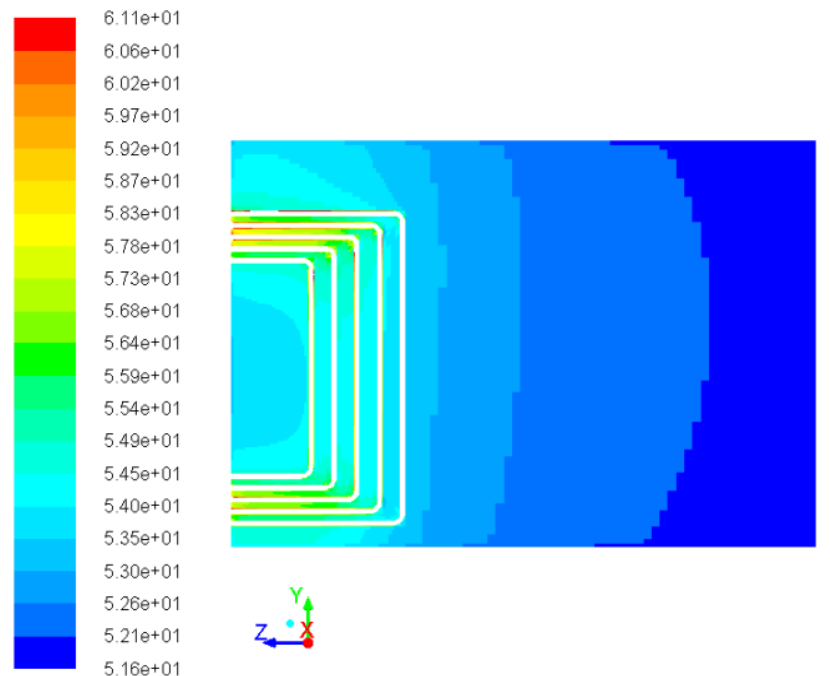

(e)

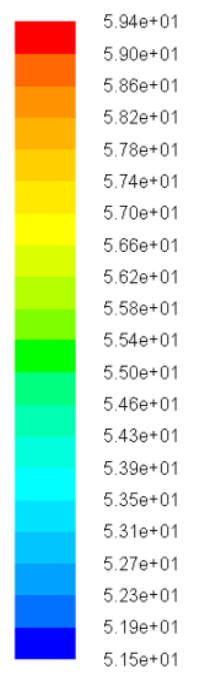

(d)
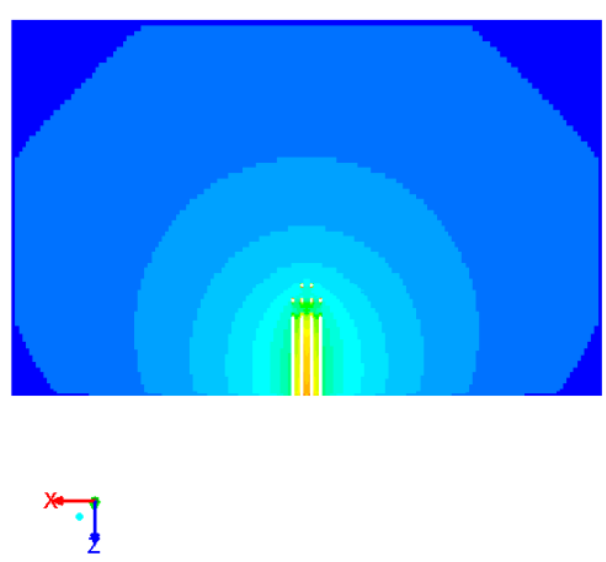

(b)
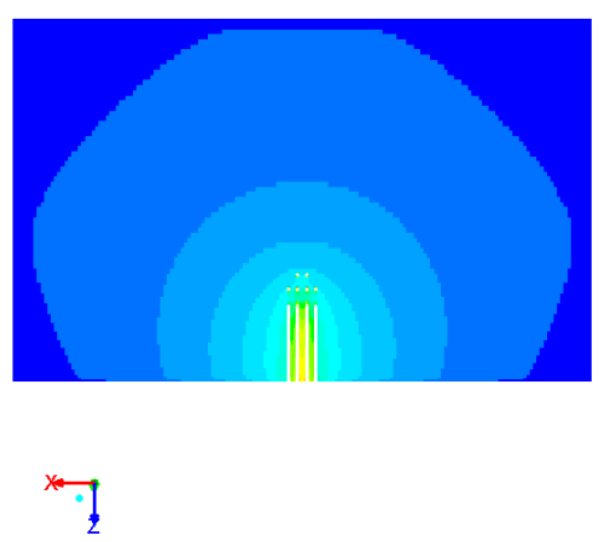

Figure 4. IRWST thermal stratification, from left to right inlet temperature is increasing. 

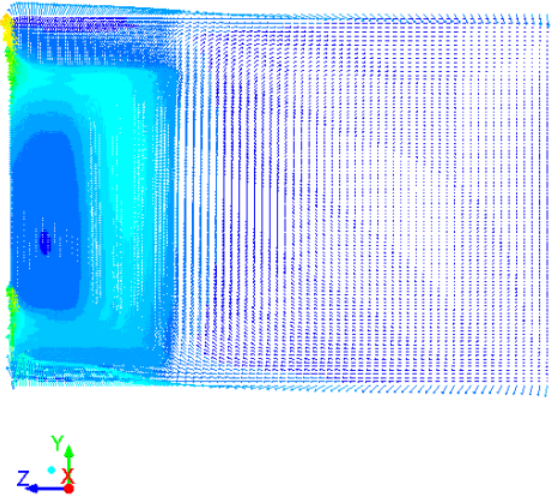

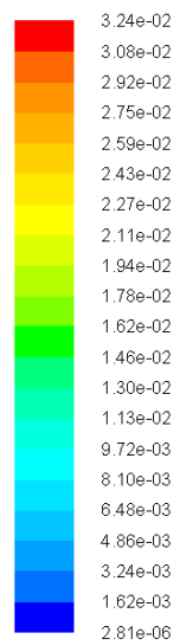

(a)
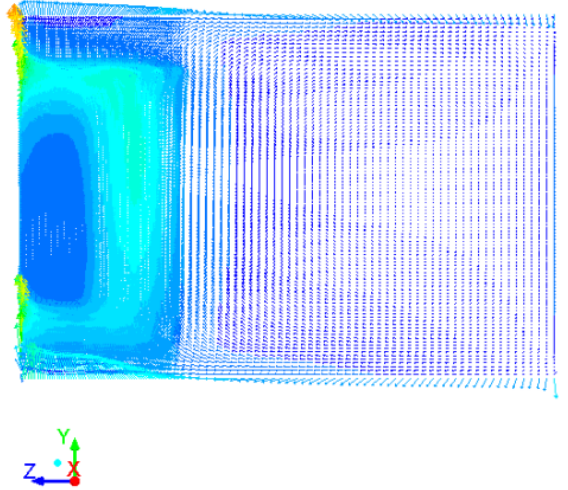

(b)
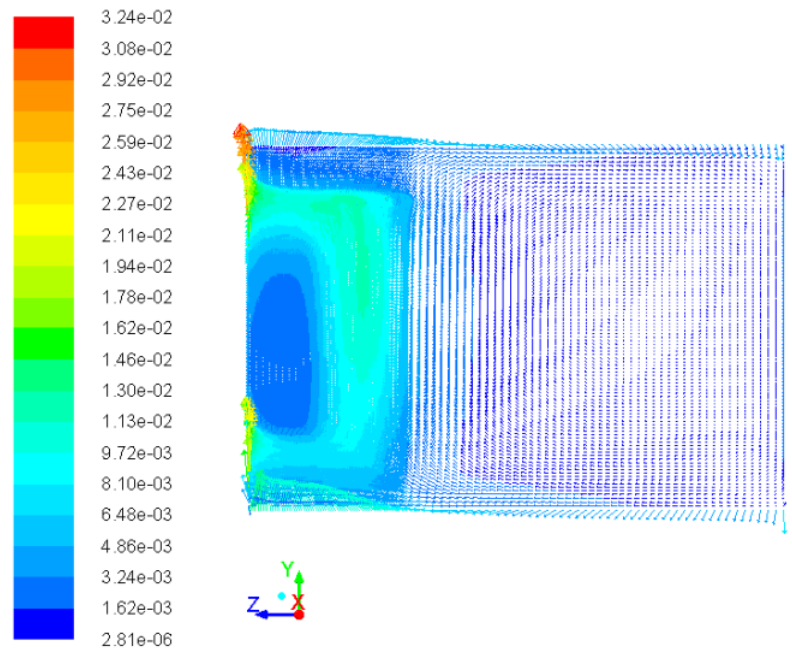

(c)

Figure 5. Natural circulation velocity vector of IRWST at different inlet temperature.

\section{Conclusions}

In this paper PRHRS is simulated with different number of C-type heat transfer tubes and different coolant inlet temperature via FLUENT software, the main conclusions are as follows:

1) Keep the total flow area of PRHR HX constant increasing the number of C-type heat exchanger tubes can increase the heat transfer area, thus heat transfer will be improved and the performance of PRHR HX will be enhanced.

2) Keep the number of C-type heat transfer tubes and overall flow constant increasing coolant inlet temperature the coolant will expand and flow velocity will increase too. The range of thermal stratification in IRWST will become larger and the velocity of natural circulation will increase.

3) With the increase in the coolant inlet temperature, outlet temperature will also increase, but the cooling rate of the system to the coolant rises. It means the heat transfer performance of PRHR HX is improved to some extent, it can guarantee the PRHRS still be safe and reliable operation when the parameters are deviated from the design conditions.

\section{Acknowledgements}

This work was financially supported by Major Projects "CAP1400 safety review technology and independent verification testing" (No.2011ZX06002010) and "CAP1400 safety review key technologies research" (No.2013 ZX06002001).

\section{REFERENCES}

[1] C.-G. Lin and Z.-S. Yu, "Passive Safety Advanced Power Plant AP1000,” Atomic Energy Press, Beijing, 2008. 
[2] K. Ikeda, Y. Makino and M. Hoshi, "Single-Phase CFD Applicability for Estimating Fluid Hot-Spot Locations in a 5*5 Fuel Rod Bundle," Nuclear Engineering and Design, Vol. 236, No. 11, 2006, pp. 1149-1154. http://dx.doi.org/10.1016/j.nucengdes.2005.11.006

[3] M. Kim, S. O. Yu and H. J. Kim, “Analyses on Fluid Flow and Heat Transfer inside Calandria Vessel of CANDU-6 Using CFD," Nuclear Engineering and Design, Vol. 236, No. 11, 2006, pp. 1155-1164. http://dx.doi.org/10.1016/j.nucengdes.2005.10.018

[4] L.-S. Li, K. Wang and X.-M. Song, "International Research Progress of CFD Application in Analysis of Nuclear Power System,” Nuclear Power Engineering, Vol. 30, No. 5, 2009, pp. 28-33.

[5] Y.-J. Gao, "Analysis of Fabrication Process for AP1000 Passive Residual Heat Removal Heat Exchanger," Nuclear Power Engineering, Vol. 32, No. 2, 2011, pp. 107-
111.

[6] R.-J. Xue, C.-C. Deng and M.-J. Peng, "Numerical Simulation of Passive Residual Heat Removal Heat Exchanger,” Atomic Energy Science and Technology, Vol. 44, No. 4, 2010, pp. 429-435.

[7] T.-Z. Ming, "Passive Residual Heat Removal Heat Exchanger Numiral Simulation and Design Research,” Huazhong University of Science and Technology, Wuhan, 2003.

[8] Y.-B. Su, J. Lu and B.-F. Bai, "Numerical Simulation of Natural Convection and Heat Transfer of Water in Cavities," Journal of Chemical Industry and Engineering (China), Vol. 58, No. 11,2007, pp. 2715-2720.

[9] S.-M. Yang and W.-Q. Tao, "Heat Transfer," 4th Edition, Higher Education Press, Beijing, 2006. 